\title{
Novel Highly Flexible Wormlike Micelles Formed by Cetylpyridinium Chloride and Trioxyethylene Monododecyl Ether Surfactants
}

\author{
FIROZ KAPADIA* and DHARMESH VARADE \\ Department of Chemistry, V. S. Patel College of Arts and Science, Bilimora, Gujarat, India. \\ ${ }^{*}$ Corresponding author E-mail: firozkapadia786@yahoo.com \\ http://dx.doi.org/10.13005/ojc/300250 \\ (Received: March 18, 2014; Accepted: April 24, 2014)

\begin{abstract}
The impact of small nonionic hydrophobic molecule, trioxyethylene monododecyl ether $\left(\mathrm{C}_{12} \mathrm{EO}_{3}\right)$, on the viscoelastic properties of aqueous solutions of cetylpyridinium chloride (CPC) is studied. As the $\mathrm{C}_{12} \mathrm{EO}_{3}$ concentration increases, the viscosity passes through a maximum. Dynamic rheological measurements revealed a comprehensive picture of how $\mathrm{C}_{12} \mathrm{EO}_{3}$ affects the different length scales in the entangled wormlike micelles. Increase in the viscosity can normally be caused by insertion of amphiphilic $\mathrm{C}_{12} \mathrm{EO}_{3}$ molecules into the cationic surfactant (CPC) layer, or micellar swelling, caused by solubilization of very hydrophobic molecules in the micellar core. The partial phase behavior and rheology of this mixed surfactant systems is studied.
\end{abstract}

Key words: Micelles, Cetylpyridinium chloride, TME, Surfactants.

\section{INTRODUCTION}

Surfactant molecules in aqueous solution self-assemble to form a variety of microstructures such as spherical micelles, wormlike micelles, vesicles and liquid crystals $^{1-5}$. These different aggregation structures have characteristic rheological properties ${ }^{6-8}$. Giant wormlike micelles are elongated, semi-flexible surfactant aggregates with outstanding rheological properties ${ }^{8-10}$. Beyond a certain threshold concentration these surfactant solutions are viscoelastic due to the transient network formed by the entangled micelles. Transition from spherical to wormlike micelles corresponds to a drastic increase of elasticity and viscosity of the fluid. The formation and properties of wormlike micelles in surfactant systems have drawn considerable interest in basic research and practical applications ${ }^{11-17}$.

In contrast to polymers, wormlike micelles are dynamic systems that persistently break and recombine; therefore they are often referred to as "living polymers". The viscoelasticity of giant micelles has been studied comprehensively $[9,10]$. Understanding the viscoelasticity of wormlike micelles is very challenging as there are numerous relevant length scales and stress relaxation 
mechanisms. However, viscoelasticity gives an intriguing insight into the connection among the molecular structure of such multifaceted fluids and their mechanical properties, and its understanding is imperative for the design and the improvement of industrial products containing giant wormlike micelles. These have many applications, including fracture fluids in oil fields, drag reduction agents and many home care, personal care and cosmetic products $^{18-20}$.

In this context, the impact of small nonionic hydrophobic molecule, trioxyethylene monododecyl ether $\left(\mathrm{C}_{12} \mathrm{EO}_{3}\right)$, on the viscoelastic properties of aqueous solutions of cetylpyridinium chloride (CPC) is studied. Upon the addition of a short chain $\mathrm{C}_{12} \mathrm{EO}_{3}$ nonionic surfactant to a dilute micellar solution of CPC induces micellar growth leading to the formation of viscoelastic solution. We have reported the partial phase behavior and rheology of this mixed surfactant systems.

\section{EXPERIMENTAL}

\section{Materials}

Cetylpyridinium chloride was purchased from Sigma/Aldrich. A highly pure sample of trioxyethylene monododecyl ether $\left(\mathrm{C}_{12} \mathrm{EO}_{3}\right)$ was purchased from Nikko Chemical Co., Japan. All the chemicals were used as received. Millipore-filtered water was used for the preparation of all the samples.

\section{Methods}

Phase diagrams

For the study of phase behaviour, ampoules containing required amount of reagents were homogenized and left in water-bath at $25{ }^{\circ} \mathrm{C}$ for equilibration. Phases were identified by visual observation.

\section{Rheological measurements}

Samples for rheological measurements were homogenized and kept in water bath at specified temperature for at least $24 \mathrm{~h}$ to ensure equilibration before performing measurements. The rheological measurements were performed in a stress-controlled rheometer, AR-G2 (TA instrument) using cone-plate geometry with the plate temperature controlled by peltier unit. A sample cover provided with the instrument was used to minimize the change in sample composition by evaporation during the measurement. Frequency sweep measurements were performed in the linear viscoelastic regime of the samples, as determined previously by dynamic strain sweep measurements. The zero-shear viscosity of the samples was determined from steady shear-rate measurement by extrapolating the viscosity shear-rate curve to zero shear-rate. Both steady and dynamic rheological experiments were performed at $25{ }^{\circ} \mathrm{C}$.

\section{RESULTS AND DISCUSSION}

\section{Phase Diagram}

The partial phase diagram of the $\mathrm{CPC} /$ $\mathrm{C}_{12} \mathrm{EO}_{3} /$ water system at $25^{\circ} \mathrm{C}$ in a water-rich region is shown in Figure 1. In water-CPC binary system micellar solution appears up to about $30 \mathrm{wt} \%$ of surfactant concentration at $25^{\circ} \mathrm{C} . \mathrm{C}_{12} \mathrm{EO}_{3}$ forms a lamellar liquid crystal coexisting with excess water in the water rich region of water- $\mathrm{C}_{12} \mathrm{EO}_{3}$ binary system. Aqueous CPC micellar solution is very fluid, but with successive addition of $\mathrm{C}_{12} \mathrm{EO}_{3}$ to a dilute micellar solution, the viscosity of the solution increases gradually at first, then rapidly and a viscous solution is observed. The minimum concentration of $4 \mathrm{wt} \% \mathrm{C}_{12} \mathrm{EO}_{3}$ is required in total system to increase the viscosity of $5 \mathrm{wt} \%$ CPC solutions significantly. The viscous solution is isotropic at rest but shows birefringence when applied a shear, such as sudden jerk. The shaded

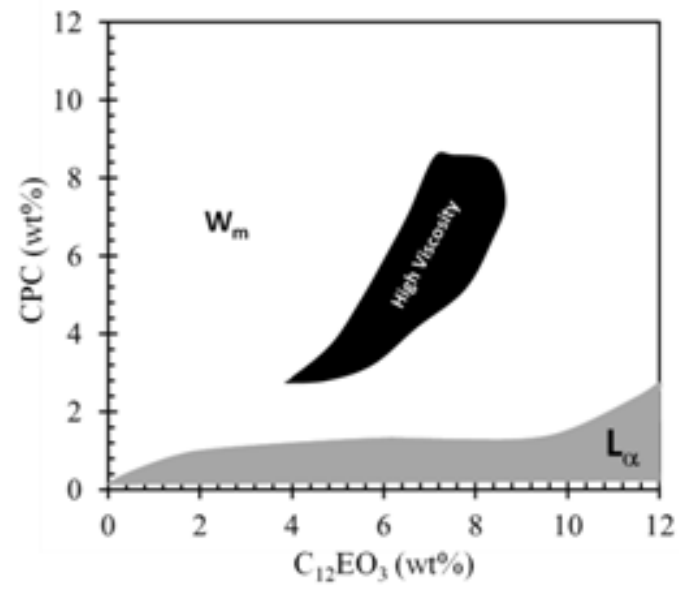

Fig. 1: Partial Phase diagram of $\mathrm{CPC} / \mathrm{C}_{12} \mathrm{EO}_{3} I$ water system at $25^{\circ} \mathrm{C} . \mathrm{W}_{\mathrm{m}}$ is the micellar phase and $\mathrm{L}_{\alpha}$ lamellar phase 
region shows the region of increased viscosity within the micellar domain of the phase diagram tentatively. With further addition of $\mathrm{C}_{12} \mathrm{EO}_{3}$, an isotropic micellar phase is still observed but the viscosity decreases.

\section{Rheological Behavior}

Rheological measurement was carried out on the semi-dilute micellar solutions of water/ $\mathrm{CPC} / \mathrm{C}_{12} \mathrm{EO}_{3}$ system in order to study the formation of wormlike micelles and viscoelasticity of the solution in the mixed surfactant system. During the entire study concentration of CPC was kept fixed at
5 wt $\%$ in water, varying the $\mathrm{C}_{12} \mathrm{EO}_{3}$ concentration expressed in weight fraction of $\mathrm{C}_{12} \mathrm{EO}_{3}$. When amphiphilic nonionic surfactants like $\mathrm{C}_{12} \mathrm{EO}_{3}$ are mixed in aqueous CPC solution, $\mathrm{C}_{12} \mathrm{EO}_{3}$ penetrate to the palisade layer of the spherical CPC aggregates and reduce their interfacial curvature leading to micellar growth; such as a sphere-rod transition is observed (Figure 2). This leads to the formation of long and flexible wormlike micelles that entangled in to a transient network structure imparting viscoelasticity to the micellar solution. Due to their transient nature, the mixed systems exhibit a novel static and dynamic property.

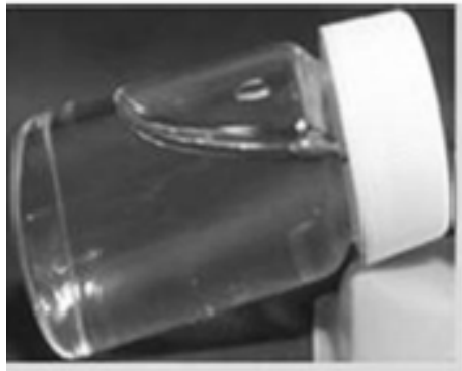

5 wt $\%$ CPC
$4.75 \mathrm{wt} \% \mathrm{C}_{12} \mathrm{EO}_{3}$

$\bowtie$

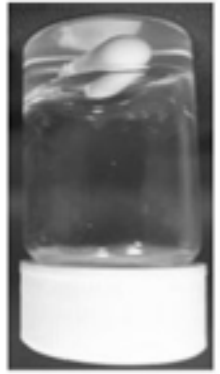

High Viscosity

Fig. 2: Photograph of sphere-to-rod transition in $\mathrm{CPC} / \mathrm{C}_{12} \mathrm{EO}_{3}$ mixed surfactant systems

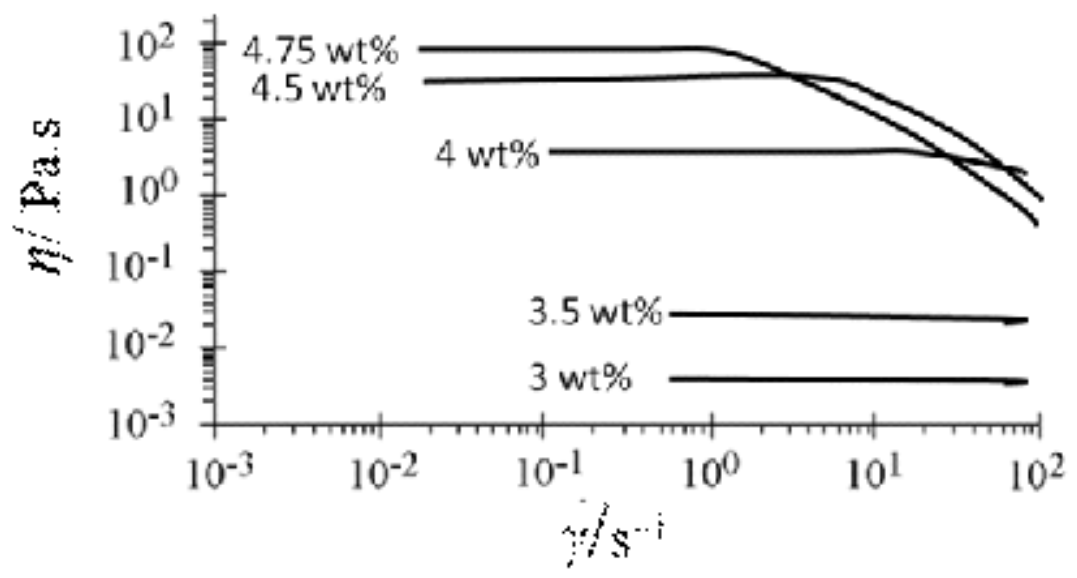

Fig. 3: Steady shear-rate plots of the water/CPC/C $\mathrm{EO}_{32}$ system at various mixing fractions of $\mathrm{C}_{12} \mathrm{EO}_{3}(\mathrm{wt} \%)$ in the total surfactant. The concentration of CPC in water is fixed at $5 \mathrm{wt} \%$

Steady viscosity measurements were performed for a $5 \mathrm{wt} \% \mathrm{CPC}+\mathrm{C}_{12} \mathrm{EO}_{3}$ system at different mixing fractions of $\mathrm{C}_{12} \mathrm{EO}_{3}$ at $25{ }^{\circ} \mathrm{C}$ as shown in Figure 3. Over a wide range of $\mathrm{C}_{12} \mathrm{EO}_{3}$ concentration (1-3 wt\%), viscosity (.) is independent of shear-rate (3نे), i.e., Newtonian flow behavior is observed, but - increases swiftly with increasing $\mathrm{C}_{12} \mathrm{EO}_{3}$ concentration around $4 \mathrm{wt} \%$. With the further increase in $\mathrm{C}_{12} \mathrm{EO}_{3}$ concentration, the viscosity increases sharply and a shear thinning is observed 
at a higher $\gamma$. This behavior is typical of worm-like micelles because above the critical $\gamma$ the viscosity decreases due to shear alignment of the micelles as well as the breaking of the structured networks. At $\mathrm{C}_{12} \mathrm{EO}_{3}$ concentration, above $4 \mathrm{wt} \%$, the samples are viscoelastic.

Variation of the zero-shear viscosity $\left(\cdot{ }_{0}\right)$ for the $5 \mathrm{wt} \% \mathrm{CPC}+\mathrm{C}_{12} \mathrm{EO}_{3}$ system at different mixing fractions of $\mathrm{C}_{12} \mathrm{EO}_{3}$ at $25^{\circ} \mathrm{C}$ as shown in Figure 4. It gives a clear idea about the effect of the concentration of $\mathrm{C}_{12} \mathrm{EO}_{3}$ at the fixed concentration of CPC on the micellar growth. The $\eta_{0}$ values have been calculated by extrapolating the viscosity data at a low-shear rate back to a zero-shear rate in the steady measurements. In aqueous CPC solution, upon increasing the $\mathrm{C}_{12} \mathrm{EO}_{3}$ content, the viscosity at first shows a slow and then a sharp increase until a maximum followed by a dramatic decrease.

Oscillatory-shear (frequency sweep) measurements were performed on the viscoelastic samples of aqueous $\mathrm{CPC} / \mathrm{C}_{12} \mathrm{EO}_{3}$ surfactant aqueous systems. A representative plot for $5 \mathrm{wt} \%$ $\mathrm{CPC}+4.75$ wt $\% \mathrm{C}_{12} \mathrm{EO}_{3}$, depicting the variation of the elastic or storage modulus ( $\left.G^{\prime}\right)$, the viscous or loss modulus $\left(G^{\prime \prime}\right)$ with oscillation frequency $(\omega)$ at $25^{\circ} \mathrm{C}$ is shown in Figure 5 . These systems show a

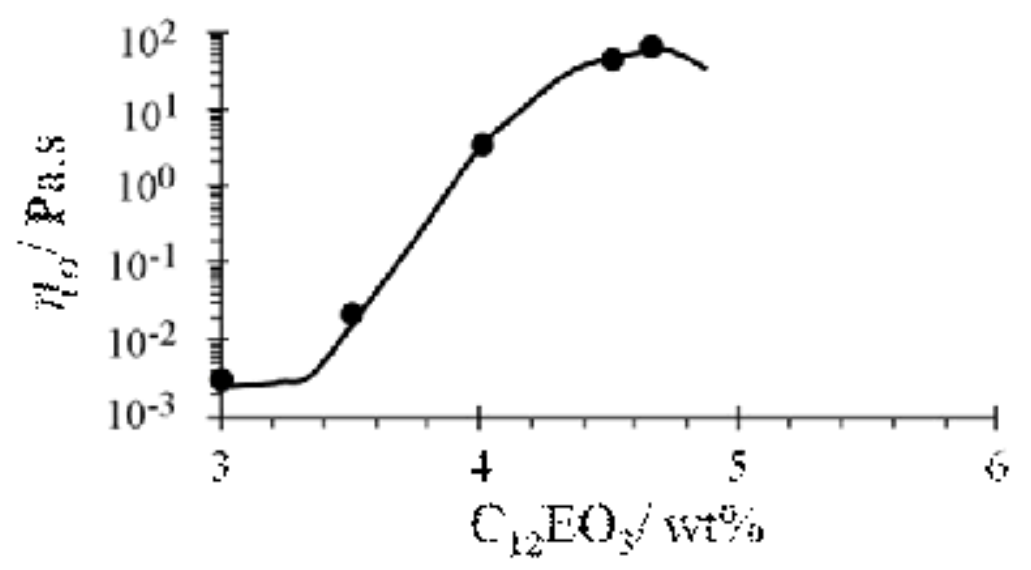

Fig. 4: Variation of the zero-shear viscosity $\left(\eta_{0}\right)$ for the water/CPC/C $\mathrm{EO}_{32}$ system at various mixing fractions of $\mathrm{C}_{12} \mathrm{EO}_{3}(\mathrm{wt} \%)$ in the total surfactant. The concentration of CPC in water is fixed at $5 \mathrm{wt} \%$

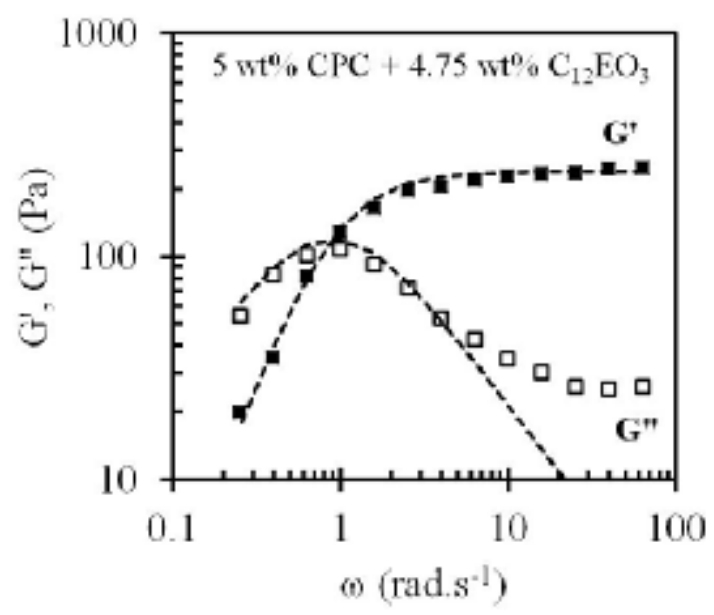

Fig. 5. Variation of the storage modulus, G', and loss modulus, $G$ ", as a function of oscillatory shear frequency $(\omega)$ in water/CPC/C $\mathrm{EO}_{32}$ system. The concentration of CPC in water is fixed at $5 \mathrm{wt} \%$ liquid-like behaviour ( $\left.G^{\prime}<G^{\prime \prime}\right)$ at the low frequency region, but both $G^{\prime}$ and $G^{\prime \prime}$ increase with $\omega$, and solidlike behaviour ( $G^{\prime}>G^{\prime \prime}$ ) is observed at the high frequency region. This is the typical viscoelastic behaviour shown by wormlike micellar solution. In the low $\omega$ region the data points of G' and G" could be fitted to Maxwell equations (shown by the dotted lines); property typical of entangled wormlike micelles forming a transient network ${ }^{12}$.

\section{CONCLUSION}

The formation of a viscoelastic solution of wormlike micelles in an aqueous solution of cetylpyridinium chloride (CPC) in presence of small amount of trioxyethylene monododecyl ether $\left(\mathrm{C}_{12} \mathrm{EO}_{3}\right)$ would be very important considering the wider applications in cosmetics and health care 
products. Micellar growth can be explained by a decrease in effective cross-sectional area per surfactant upon addition of $\mathrm{C}_{12} \mathrm{EO}_{3}$. It is interesting to point out that there is no report on the formation of wormlike micelles in $\mathrm{CPC} / \mathrm{C}_{12} \mathrm{EO}_{3}$ system so far and such a system may have a huge capability as a smart material.

\section{REFERENCES}

1. M. J. Rosen, Surfactants and Interfacial Phenomena, Wiley, New York, NY, $2^{\text {nd }}$ edn., 1989.

2. D. Myers, Surfactant Science and Technology, VCH, New York, 1988.

3. Solution Chemistry of Surfactants, ed. K. L. Mittal, Plenum, New York, 1979, vol. 1 and 2.

4. Solution Behaviour of Surfactants, ed. K. L. Mittal and E. J. Fendler, Plenum, New York, 1982, 1(2).

5. Surfactants, ed. Th. F. Tadros, Academic Press, London, 1984.

6. C. Rodríguez-Abreu, L. K. Shrestha, D. Varade, K. Aramaki, A. Maestro, A.L. Quintela, C. Solans, Langmuir, 2007, 23, 11007.

7. V. Kantsler, E. Segre and V. Steinberg, EPL, 2008, 82, 58005.

8. Z. Chu, C. A. Dreiss, Y. Feng, Chem. Soc. Rev. 2013, 42, 7174.

9. C. A. Dreiss, Soft Matter, 2007, 3, 956.

10. G. Palazzo, Soft Matter, 2013, 9, 10668.

11. A. Parker, W. Fieber, Soft Matter, 2013, 9,
1203.

12. Varade, D., Rodríguez-Abreu, C., Shrestha, L.K., Aramaki, K. J. Phys. Chem. B, 2007, 111, 10438.

13. Varade, D., Ushiyama, K., Shrestha, L.K., Aramaki, K. J. Colloid and Interface Science, 2007, 312, 489.

14. B. Bharti, M. Xue, J. Meissner, V. Cristiglio, G. H. Findenegg, J. Am. Chem. Soc., 2012, 134, 14756.

15. T. S. Davies, A. M. Ketner, S. R. Raghavan, J. Am. Chem. Soc., 2006, 128, 6669.

16. Z. Li, M. A. Hillmyer, T. P. Lodge, Nano Lett. 2006, 6, 1245.

17. E. Sabadini, R. F. S. Ungarato, P. B. Miranda, Langmuir, 2014, 30, 727.

18. J. Yang, Curr. Opin. Colloid Interface Sci. 2002, 7, 276.

19. L. M. Walker, Curr. Opin. Colloid Interface Sci. 2001, 6, 451.

20. D. Varade, K. Haraguchi, Soft Matter 2012, 8, 3743. 